\title{
Expressão de pontos de vista e os meios digitais
}

Expression of viewpoints and The Digital Media

\author{
> Marqueto, Priscilla \\ Universidade de São Paulo, Brasil \\ marchetto@sc.usp.br
}

\author{
> Tramontano, Marcelo \\ Universidade de São Paulo, Brasil \\ tramont@sc.usp.br
}

\begin{abstract}
The evaluation of previous research carried out by Nomads.usp - Center of Interactive Living Studies - which used several classical methodological instruments of qualitative research in order to understand urban and social contexts, found limits of these tools when they were employed to encompass nuances related to ways of life, worldviews and viewpoints of surveyed individuals. The aim of this reseach is to verify the limits and the possibilities of using two activities conceived for usage in cultural events with audience's presence - Digital Graffiti and Comment's Projection -, in a matter of utilizing it as well as procedures for gathering informations about its audiences by proposing communication processes and dialogs, with the aid of digital media.
\end{abstract}

Keywords: Comunicação; Pontos de vista; Meios digitais; Graffiti digital.

\section{Introdução}

Cada vez mais, experiências no âmbito acadêmico têm apontado para a demanda de entrecruzamentos entre campos disciplinares, dada a complexidade dos contextos pesquisados e de procedimentos que têm buscado abarcar, parcialmente, tal complexidade. Existem, hoje, investigaçóes que reúnem saberes de campos disciplinares diversos, formando um todo capaz de aproximar-se mais de realidades, objetivos investigativos e corroborando para a constituição de um horizonte teórico e de pesquisa mais amplo, aberto, complexo e rico.

Um pouco do que se pretende compartilhar nesse trabalho, desenvolvido ao longo de três anos, são experiências, verificaçóes, observaçôes e compreensôes a partir da experimentação de procedimentos realizados com público em eventos culturais e remotamente por uma plataforma de comentários online.

A pesquisa foi conduzida tentando ancorar a discussão e uso de procedimentos metodológicos em pesquisa qualitativa, se apoiando em campos disciplinares, nâo unicamente da arquitetura e urbanismo, e que apontem para a potencialidade dos procedimentos testados. Sem a intenção de esgotar o tema e suas possibilidades, mas deixando o legado de impressóes de uma breve investigação empírica e teórica nessa área.

\section{Procedimentos e os meios digitais}

Por que testar outras ferramentas e suportes na obtenção de informações?

$\mathrm{O}$ exame de resultados de pesquisas anteriores realizadas pelo Nomads.usp - Núcleo de Estudos de Habitares Interativos -, em que foram utilizados vários instrumentos metodológicos clássicos de pesquisa qualitativa a fim de entender contextos urbano e social, revelou limites desses instrumentos em suas formataçóes mais tradicionais, quando se desejava abarcar nuances referentes a modos de vida, visóes de mundo e pontos de vistas de indivíduos pesquisados.

\section{Projeto Territórios Hibridos e os procedimentos testados} A partir dessas leituras, e das demandas percebidas em campo, em termos de coleta de dados, posturas de pesquisadores, os procedimentos testados foram estruturados, baseando-se em uma problemática de que forma poderíamos acessar informaçóes sobre um determinado contexto urbano e social, que nos métodos clássicos empreendidos em anos anteriores, não se havia acessado. Para isso, concebeu-se procedimentos que fugissem à uma formalidade acadêmica, e que acontecessem no âmbito de uma atmosfera de informalidade e maior descontraçáo, como no caso do: Graffiti Digital e Projeção de Comentários.

Os dois procedimentos testados - Graffiti Digital e Projeção de Comentários - somente foram possíveis da forma que foram realizados por estarem inseridos em um grande projeto de políticas públicas, financiado pela Fundação de Amparo à Pesquisa do Estado de São Paulo - FAPESP, o Projeto Territórios Híbridos: comunidades, açóes culturais e meios digitas.

O projeto Territórios Híbridos, situa-se hoje em uma linha de fomento de políticas públicas, foi desenvolvido pelo Nomads.usp, com experiência de projeto anterior nessa mesma linha de fomento. 
O Territórios Híbridos se articulou por meio de parcerias com orgáos do terceiro setor, como coletivos, ONGs, bandas, além de ter parceria com orgãos públicos ligados à cultura e universidades, inclusive internacionais, ampliando o alcance do projeto, reunindo visôes de mundo distintas desde sua organização, produção até a realização das açôes.

\section{Graffiti Digital e Projeção de Comentários}

O Graffiti Digital foi concebido a partir da vontade de se aproximar realidades distintas, pessoas, universos, pontos de vista, usando, não somente, mas principalmente, linguagem não-oral, pelo uso das interfaces gráficas pela qual foram realizados os graffitis digitais.

O segundo procedimento a ser apresentado que usou meios digitais trata-se da Projeçáo de Comentários. Foi implementado durante a realização de eventos e açôes do projeto, com o intuito de dar voz ao público, tanto presencial, quanto o público que acompanhava remotamente pela transmissão de vídeo por twittcam. Os comentários coletados foram projetados durante os eventos e esse procedimento foi amplamente usado durante a duraçáo do projeto.

Os procedimentos testados buscaram igualmente criar canais para que as pessoas de um dado contexto expressassem seus pontos de vista, suas visóes de mundo, pontos de vista, e que a partir de processos comunicacionais pautados pela interlocução, remota ou presencial, pudessem também ver parte dessas posturas revisadas ou entendidas sob outras perspectivas.

Esses dois procedimentos foram concebidos para uso em eventos culturais com presença de público, no sentido de utilizá-los como procedimentos de obtenção de informação sobre seus públicos, e também estimulando processos comunicacionais e interlocuçóes com auxílio de meios digitais.

Uma das premissas do grupo de pesquisa Nomads.usp, é a utilização de tecnologias de baixo custo e facil acesso, permitindo possíveis replicaçóes futuras por diferentes grupos e pessoas. Portanto, para o Graffiti Digital, foi utilizado um software de baixo custo, o Touch Tag, instalado em um tablet ligado a um projetor. No caso da Projeçáo de Comentários, foi criada uma plataforma de comentários no site do Projeto Territórios Híbridos, de forma que, durante os eventos, os pesquisadores circulavam com notebooks, conversando com as pessoas presents e convidando-os a darem sua opiniáo através de um comentário que ficaria armazenado no site do projeto, e era projetado simultaneamente no teláo do evento.

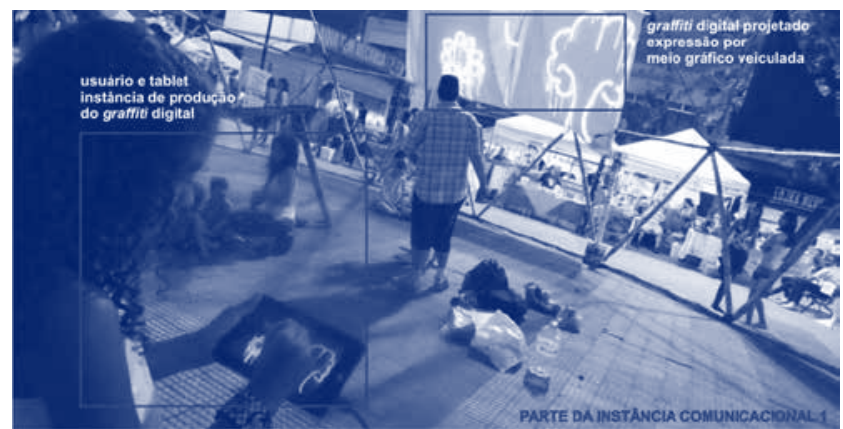

Figura 1: Usuário grafitando digitalmente durante evento em São Carlos. NOMADS.USP, 2013.

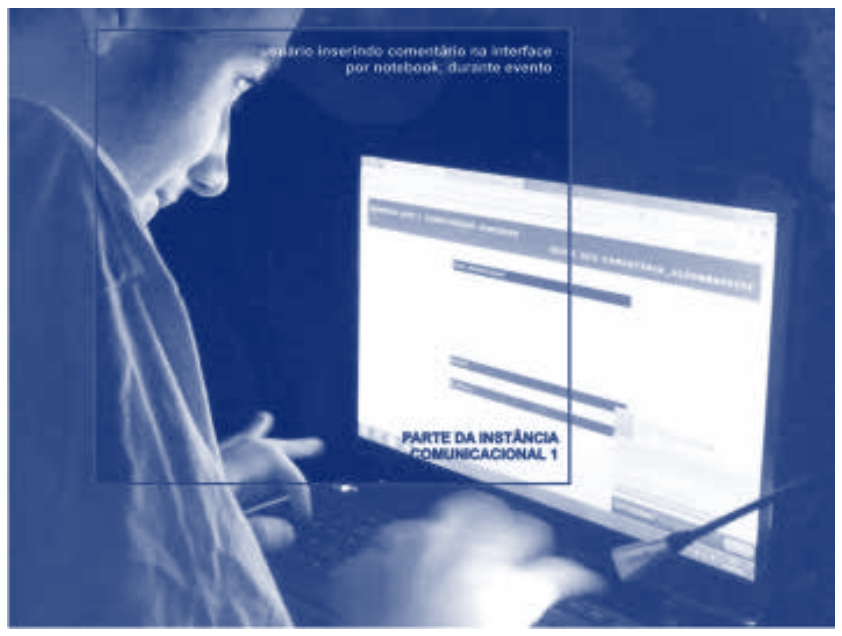

Figura 2: Usuário postando comentário durante evento pela Interface de Comentários do Projeto. NOMADS.USP, 2013.

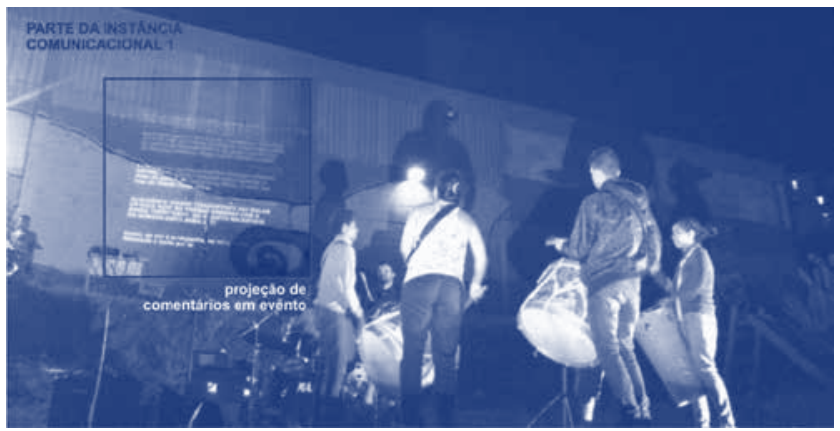

Figura Э: Comentários sendo projetados durante evento com banda musical tocando em Cidade Tiradentes, São Paulo. NOMADS.USP, 2013.

\section{Instâncias e Processos Comunicacionais, Limites e Potencialidades}

A comunicação recobre, então, vastas extensóes do universo humano e se apresenta como uma das chaves para sua compreensão. Martino, 2004, p. 12

No âmbito do Graffiti Digital

O objetivo dessa ação foi envolver públicos a princípio resistentes à presença do graffiti pintado na cidade, esperando provocar reflexôes a partir de um estranhamento. Também se quis usar as potencialidades do meio digital para sugerir aos grafiteiros a sensação de estar grafitando em paredes de uma cidade distante, remotamente, e de dimensão, contextos urbano e social distintos da sua própria.

Uma qualidade importante do Graffiti Digital é o fato de a linguagem gráfica ser acessível a muitas idades, por não pressupor conhecimento específico. Desde crianças se sentem atraídas a usar o tablet e a grafitar em uma superfície, até adultos e pessoas idosas. Isso também se torna mais fácil pelo manuseio simples do programa utilizado. Além de ter um operacional bastante simplificado, ele 
tem a capacidade de potencializar o desenho e criar rapidamente efeitos gráficos especiais.

A interface do Touch Tag permite que mesmo pessoas pouco familiarizadas com essa prática produzam desenhos ou esboços, o que provavelmente náo aconteceria se a atividade proposta fosse grafitar em uma parede pela primeira vez com spray, sem um conhecimento básico do universo do graffiti e das várias técnicas do uso do spray.

$\mathrm{Na}$ medida em que o usuário com o tablet começa a grafitar, pode-se perceber uma instância individual, entre o usuário e o tablet que, ao se propor a grafitar, cria nesse âmbito um momento reflexivo, seja a partir de referências próprias, seja sob influências do contexto em que está imerso, seja sob influências de graffitis anteriores. Tal ação é complementada pela comunicação que se dá a partir da projeção desse graffiti em uma superfície para que o coletivo o veja.

Nesse âmbito da produção do graffiti digital, há um caráter de elaboração pelo indivíduo, que, nesse sentido, tece relaçôes com o que estamos entendendo nessa pesquisa como o "falar consigo mesmo". O desenho é produzido a partir de uma reflexão sobre questôes individuais, que podem se constituir a partir de instâncias coletivas, referências anteriores, prontas a serem revistas continuamente na vida cotidiana. Assim, uma leitura possível é que, nessa produção do graffiti que, quando projetado e exibido para outras pessoas, se constitui em um processo comunicacional, possam estar refletidos pontos de vistas, visóes de mundo, e parte da experiência do indivíduo, como colocou Dewey (1934), que se vê compartilhada nesse âmbito, expressa graficamente. Para o autor, não se pode determinar onde termina o indivíduo e onde começam o entorno natural ou a sociedade. O que é meu, é meu justamente porque eu o elaborei em relação ao mundo, e não porque eu já tenha nascido possuindo-o, separadamente do mundo. Uma experiência é "minha" porque eu estou incluído nela.

Assim, se a prática do graffiti se dá em um âmbito coletivo no procedimento testado, elas são experimentadas de maneiras individuais pelas pessoas do público, corroborando a ideia de Williams (1989 apud RIBEIRO, 2004) que defende que a produção do que ele chama de "significados" - as vias de expressão de uma pessoa podem ser originadas de uma experiência compartilhada. No caso do Graffiti Digital, tal experiência deriva-se de sua projeção e exibição, e na apreensão dessa expressão pelo público. Entendemos também esse processo como uma parte do "não falar sozinho", a partir das reverberaçóes e feedbacks que esse "falar consigo mesmo" pode estimular. Isso estabelece o canal de comunicação entre o indíviduo e público, que, na sequencia, como será tratado neste capítulo, gera um processo de interlocução contínua pela produção dos graffitis e pelas pessoas que estão interagindo nesse âmbito, por meio gráfico.

A segunda instância comunicacional do Graffiti Digital é gerada a partir da possibilidade de interlocução com o público que, ao ver o que está sendo grafitado, pode ser motivado a desenhar algo, tanto através de linguagens textuais, quanto por vias de expressão gráfica, grafitando também, talvez, a partir das referências projetadas anteriormente.

Nesta segunda instância, há também a possibilidade de uma interlocuçáo ampliada pelo uso dos meios digitais por comunicaçáo remota. Essa possibilidade testada no âmbito do Projeto Territórios
Híbridos consiste em duas pessoas grafitando à distância uma da outra. Uma pessoa está em um dado contexto físico produzindo no tablet um desenho que é enviado via internet e projetado em tempo real em um outro lugar físico, onde outra pessoa está igualmente desenhando em um tablet e tem seu graffiti projetado também em tempo real no local físico onde se encontra a primeira pessoa. Isso gera uma interlocução à distância utilizando-se de recursos gráficos, constituindo uma forma de comunicação que mescla ambientes virtuais e físicos.

O emprego dos meios digitais, nesse sentido, permite que um graffiti digital feito por um indivíduo em dado contexto, no caso do procedimento, Sáo Carlos, considerando as referências individuais e as influências do entorno naquele momento que estão implicadas nele, seja projetado em tempo real em outro local, nesse caso, Belo Horizonte, refletindo parte daquele âmbito de São Carlos pela expressão dada no Graffiti Digital. Isso faz com que o público que esteja assistindo a essa projeção em Belo Horizonte perceba essa expressão, e que possa estabelecer relaçóes com ela, tanto em termos de estranhamento, quanto de identificação. A partir disso, indivíduos desse público em Belo Horizonte também estão grafitando e tendo seus graffitis projetados em São Carlos, com as mesmas possibilidades de estranhamento ou não. Isso permite, no caso de identificação, apreender características estilísticas que se relacionam, por exemplo. Ou no caso de estranhamento, perceber uma absoluta distinção entre os traços do desenho apresentado.

Isso interessa a este trabalho na medida em que estamos entendendo também essas instâncias comunicacionais como instâncias de negociação e de articulação de diferentes pontos de vistas, posturas, visóes de mundo e modos de vida que se distinguem pelas particularidades individuais.

\section{No âmbito da Projeção de Comentários}

A iniciativa de propor a coleta e projeção de comentários durante a realização dos eventos no âmbito do Projeto Territórios Híbridos, partiu do interesse em criar um canal de interlocução com o público. Uma forma de ouvir suas opinióes acerca dos eventos e das temáticas centrais de cada um. Outro fator importante, era a intenção de que o público à distância também pudesse tomar parte da discussão colocada. Já que a partir de certo momento do projeto o núcleo estruturou-se para transmitir o vídeo do evento ao vivo pela internet. Ou seja, pessoas de qualquer parte do mundo poderíam assistir ao que estava acontecendo, e em tempo real podiam expressar suas opinióes e pontos de vista, que eram projetados durante o evento.

A Projeção de Comentários se configura, principalmente, por duas instâncias comunicacionais. A primeira, é quando os pesquisadores abordam pessoas em um determinado evento e as convidam a comentar e expressar suas opiniôes sobre um determinado tema, usando os notebooks disponibilizados pelos pesquisadores durante o evento. Os comentários produzidos por cada pessoa são postados e simultaneamente publicados online no site do projeto, que pode ser acessado por qualquer pessoa e de qualquer lugar, e esses comentários também projetados durante o evento para que todos os presentes .

Nessa primeira instância, tal qual no Graffiti Digital, o indivíduo produz uma escrita a partir de uma percepçáo e reflexão individual 
sobre um tema levantado no evento. Essa instância individual também sobre influência do que a circunda, das conversas mantidas anteriormente ao ato de desenhar e da leitura dos comentários de outrem projetados. Nesse sentido, como apresentamos no procedimento anterior, o indivíduo estabelece uma relaçáo de "falar consigo mesmo", de uma elaboraçáo própria a partir de uma dada experiência individual. Coloca-se como um "não falar sozinho" na medida em que os comentários são vistos pelo público presente no evento, e por outras pessoas que acessam remotamente o site, lêem os comentários à distância e têm também a possibilidade de escrever e ser lidos pelo público local.

Nesse processo comunicacional, a abrangência da interface é maior por ser disponibilizada em ambiente web. Pode-se tecer uma relação com o que nos apresenta o sociólogo Castells (2003, p. 7) quando se refere à internet como uma ferramenta comunicacional que viabiliza "a comunicação de muitos com muitos” em escala global. Isso significa que não podemos, no caso da Projeção de Comentários, determinar o alcance possível dessas possbilidades comunicacionais, e também não se pode estabelecer uma duração precisa da ação enquanto a plataforma de Comentários estiver disponibilizada online, já que, mesmo após o final do evento, essa comunicação pode continuar sendo feita de forma assíncrona. Essa ideia de uma comunicação ampliada também é compartilhada e entendida por Fragoso, Rebs e Barth (2011) como uma abertura para interações e articulações entre muitas pessoas. Para esses autores, ela também se constitui como "prática social", interrelacionando processos comunicacionais e sociais, - como foi introduzido no capítulo 1 desta dissertação -, o que conduz ao âmbito da segunda instância comunicacional apreendida na Projeção de Comentários.

A segunda forma de abordagem é online. As pessoas são convidadas a comentar de onde estiverem, em alguns casos a partir da transmissão de vídeo online simultaneamente à realizaçáo do evento, foram recebidos comentários de diversos lugares do Brasil e do mundo.

Essa forma de participar de um evento, mesmo que à distância, a partir do compartilhamento de um ponto de vista particular que será projetado no evento, coloca-se como um interesse da pesquisa de dar voz a essas pessoas que, à distância, se interessaram de alguma forma pelo que estava sendo discutido. Isso permite ampliar os entendimentos possíveis acerca de uma série de questóes como a relevância do tema levantado, quem está interessado em discutir esse assunto, onde vivem ou onde estáo as pessoas que demonstraram esse interesse ou, entáo, de fato o público se mostrou interessado em discutir isso. São questôes que contribuíram para respaldar tomadas de decisóes durante esta pesquisa de mestrado e durante o Projeto Territórios Híbridos.

Além disso, o uso da Projeção de Comentários, é uma forma de ampliar a instância comunicacional que, dessa forma, extrapola os limites físicos do evento e permite que pessoas de diferentes contextos geográficos, urbanos e culturais possam expressar suas opiniôes e visóes de mundo, reunindo em uma plataforma um rico banco de informaçóes e relatos muito diversos. Ao contrário, por exemplo, da Rádio de Rua cujo alcance está limitado ao seu entorno físico, durante sua realização. No caso da Projeção de Comentários, essa ampliação da instância comunicacional para uma instância híbrida somente é viabilizada pelo seu caráter web-based.

\section{Considerações Finais}

Os dois procedimentos testados se constituem como possibilidades para obtenção de informaçóes em pesquisa qualitativa permitindo empreender interlocuçóes diversas, a partir de processos comunicacionais, com o uso dos meios digitais ou não. Isso representa, para este tabalho, um avanço no sentido de perceber questóes mais subjetivas e menos acessíveis quando se usam outros instrumentos de investigação qualitativa.

Nos procedimentos realizados, um aspecto perpassa todos eles: sua capacidade de permitir que todo o coletivo tenha acesso a um pouco do que se está pensando naquele lugar, durante o evento, do pensamento daquela massa, daquele coletivo, que é expresso pela escrita no âmbito da Projeção de Comentários ou por interface gráfica no Graffiti digital.

Em ambos, os processos comunicacionais se colocam como um âmbito de possível articulação e de compartilhamento, trocas, com possibilidades de feedback, contínuo ou não, síncrono ou assíncrono. Os meios digitais empreendidos se apresentam como constituidores de processos comunicacionais que podem ser alterados, revistos, e com potencialidades a "serem descobertas por experiência, nâo proclamadas de antemão”. (CASTELLS, 2003, p. 10).

Nesta pesquisa, estava-se buscando verificar potencialidades de procedimentos para coleta de informações, esse potencial não somente foi percebido como teve-se um acréscimo ao que foi emergindo durante os procedimentos.

A possibilidade de feedback foi observada também no âmbito dos procedimentos o que acrescentou uma complexização nas informaçóes obtidas por esses procedimentos, que também diferentemente de procedimentos de métodos clássicos, as informaçóes coletadas eram instantaneamente compartilhadas com o público, seja pela Projeçáo e Interface de Comentários, seja pelo Graffiti Digital projetado, levando a pensar na combinação desses procedimentos como outras formas de acréscimo às coletas.

A partir desse estudo percebem-se caminhos possíveis para outras investigaçóes. Pode-se aprofundar no uso de interfaces com grupos e pessoas, pode-se a partir de uma sistematização rigorosa e com ampla pesquisa empírica de validação pensar na construção de um método para coleta de dados a partir dos procedimentos propostos, desde que guiados pelas instâncias necessárias e com recorte preciso do que se deseja pesquisa, e o que mais poderia ser pesquisado. Tem-se uma perspectiva de muitas possibilidades de usos e apropriaçóes do que foi testado ou do que pode ser feito a partir disso, que é entendido como uma das contribuiçóes deste trabalho, propiciar interlocuçóes entre pesquisas.

\section{References}

Castells, M. (2003). A Galáxia da Internet. Rio de Janeiro: Jorge Zahar. Dewey, J. (1934). Art as Experience. New York.

Martino, L. C. (2004). História e Identidade: apontamentos epistemológicos sobre a fundação e fundamentação do campo comunicacional. Revista Eletrônica E-compós. Disponível em: <http://www.compos.org.br/e-compos>. 